\title{
Analisis Multivariat Ukuran Tubuh Sebagai Penduga Hubungan Kekerabatan Subpopulasi Sapi Pesisir Di Sumatera Barat
}

\author{
Sarbaini $^{1}$ \\ Fakultas Peternakan Universitas Andalas Padang
}

\begin{abstract}
The discriminate function and canonical correlation analysis were carried out in order to differentiate between subpopulations, and to determine the discriminate variables which may contribute on the differentiation of the three Pesisir cattle subpopulations in West Sumatra. Around 528 of Pesisir cattle's were as sample. They were distributed in three subpopulations in West Sumatra: Pesisir Selatan, Padang Pariaman, and Agam districts. Body measurement data were collected for body weight, body length, withers height, hip height, chest width, chest depth, chest girth, hip width, head length, and head width. The data were statistically analyzed by using discriminate function. The results of the study found that the Pesisisr cattle growing in Padang Pariaman showed very different in body measurement with those growing in Agam and Pesisir Selatan subpopulation. The results also indicated that withers height, hip height, head width, body weight, and head length were the most importance body measurement to differentiate amongst the Pesisir cattle population in West Sumatra.
\end{abstract}

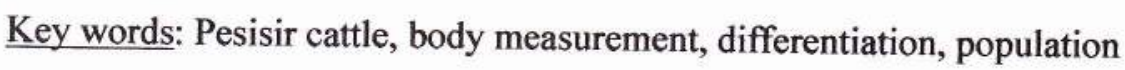

\section{Pendahuluan}

Pada tahun 2001 populasi ternak sapi potong daerah ini pada tahun 2001 tercatat sebanyak 501.356 ekor (BPS Sumatera Barat, 2001). Sebahagian besar dari populasi ini terdiri dari bangsa - bangsa sapi lokal setempat, sapi Bali, peranakan Ongole serta berbagai hasil persilangannya, serta sebagian kecil lainnya berupa bangsa sapi impor, seperti; Simmental, Charolais, dan berbagai hasil persilangannya dengan ternak lokal.

Bangsa sapi lokal Sumatera Barat dikenal dengan nama sapi Pesisir dan merupakan salah satu bangsa sapi khas lokal Indonesia (Utoyo et al., 1996), sapi ini memiliki tubuh berukuran lebih kecil dibandingkan dengan beberapa sapi lokal Indonesia lainnya, misalnya bobot hidup umur dewasa hanya 85,9 $\%$ dari sapi Madura (Siregar et al., 1985), 70,8 \% dari sapi Bali, dan 48,3 $\%$ dari sapi PO (Fapet IPB-Ditjennak, 1985). Bangsa sapi ini memegang peranan penting baik dalam pengadaan ternak potong untuk keperluan sehari - hari maupun ternak qurban Idul Adha di Sumatera Barat.

1).

Sarbaini, Dr, MSc, Ir. Lektor Kepala Genetika dan Pemuliaan Ternak pada Program Studi Produksi Ternak, Fakultas Peternakan Universitas Andalas 
Populasi sapi ini khususnya dikenal dan dijumpai di Kabupaten Pesisir Selatan dan belum ada informasi apakah bangsa sapi Pesisir ini juga ditemukan di wilayah lain Sumatera Barat atau wilayah lainnya di Sumatera.

Ukuran-ukuran tubuh telah lama digunakan untuk membedakan atau mengidentifikasi satu spesies. Metoda ini juga telah banyak digunakan untuk membedakan antar bangsa ternak, seperti Herrera et al. (1996) pada lima bangsa kambing Andalusia dan Suparyanto et al. (1999) pada domba ekor tipis dan domba ekor gemuk Indonesia.

Oleh sebab itu, penelitian ini dilakukan dengan tujuan untuk mengidentifikasi atau membedakan bangsa sapi Pesisir dengan sapi lokal lainnya berdasarkan pada ukuranukuran tubuh.

\section{Materi Dan Metoda}

Penelitian ini dilakukan di tiga subpopulasi/kabupaten di Sumatera Barat, yakni: kabupaten Pesisir Selatan (Kecamatan Ranah Pesisir), Padang Pariaman (Kecamatan Ulakan - Tapakis) dan Agam (Kecamatan Tanjung Mutiara). Sampel sapi diambil dari masing - masing sub populasi secara acak (Steel dan Torrie, 1995).

Sampel pada penelitian ini adalah sapi jantan dan betina yang dipelihara masyarakat dengan lima tingkat umur $(0,5-1,1-2,2-2,5,3$ $-3,5$, dan 4 tahun atau lebih). Ukuran - ukuran tubuh yang diamati adalah bobot badan, panjang badan, tinggi pundak, lebar dada, lingkar dada, tinggi pinggul, lebar pinggul, panjang kepala dan lebar kepala. Total sampel yang diamati pada penelitian ini adalah sebanyak 527 ekor yang terdiri dari 286 ekor pada kabupaten Pesisir Selatan, 111 pada kabupaten Padang Pariaman, dan 131 ekor pada Kabupaten Agam.

Analisis fungsi diskriminan digunakan untuk menghasilkan kemungkinan terbaik untuk memisahkan dua atau lebih kelompok inidividu (Manly, 1986).

Pendekatan yang digunakan dalam analisis diskriminan adalah dengan menggunakan jarak Mahalanobis (Manly, 1986; dan Siswadi dan Suharjo, 1997), dengan persamaan (Manly, 1986):

$$
D^{2}=\sum_{r=1}^{p} \sum_{s=1}^{p}\left(x_{\mathrm{p}}-\mu_{p}\right) v^{\mathrm{rs}}\left(x_{\mathrm{s}}-\mu_{s}\right)
$$

Dalam menduga parameter kuantitatif yang memberikan pengaruh terbesar terhadap penyebab terjadinya pengelompokan antar subpopulasi atau untuk mengidentifikasi hubungan diantara dua set peubah digunakan analisis korelasi kanonik. Analisis ini dilakukan dengan mencari kombinasi linier peubah - peubah pada set pertama yang berkorelasi paling tinggi dengan kombinasi linier peubah peubah pada set kedua (Lebart et al., 1984).

Program statistik SAS ver. 6.12 dengan prosedur PROC. DISCRIM digunakan untuk membantu perhitungan analisis statistik ini.

\section{Hasil Dan Pembahasan}

\section{Analisis diskriminan}

Analisis fungsi diskriminan linier terhadap semua ukuran - ukuran tubuh pada tiga subpopulasi sapi lokal Sumatera Barat menghasilkan pengelompokan menurut subpopulasi 
Tabel 1. Pengelompokan Sapi Lokal Sumatera Barat Menurut Subpopulasi Berdasarkan Analisis Fungsi Diskriminan

\begin{tabular}{lccccc}
\hline Subpopulasi & \multicolumn{3}{c}{ Subpopulasi } & \\
\cline { 2 - 5 } & & Pesisir Selatan & Padang Pariaman & Agam & Total \\
\hline Pesisir Selatan & $n$ & 247 & 17 & 22 & 286 \\
& $(\%)$ & 86,36 & 5,94 & 7,69 & 100 \\
\multicolumn{2}{r}{ Padang Pariaman $n$} & 30 & 78 & 3 & 111 \\
\multirow{5}{*}{ Agam } & $(\%)$ & 27,03 & 70,27 & 2,70 & 100 \\
& $n$ & 68 & 11 & 52 & 131 \\
& $(\%)$ & 51,91 & 8,40 & 39,69 & 100 \\
\hline \multirow{2}{*}{ Total } & $n$ & 345 & 106 & 77 & 528 \\
& $(\%)$ & 65,34 & 20,08 & 14,58 & 100 \\
\hline
\end{tabular}

atau daerah asal sebagaimana disajikan pada Tabel 1 berikut.

Dari Tabel 1 di atas dapat dikemukakan bahwa tingkat kesesuaian pengelompokan sapi lokal Sumatera Barat menurut subpopulasi berkisar antara 39,69\% - 86,36\%. Kesesuaian tertinggi ditemukan pada subpopulasi Pesisir Selatan (86,36 \%), kemudian diikuti oleh Padang Pariaman (70,27 \%) dan terendah dalam subpopulasi Agam (39,69 \%). Pada subpopulasi Pesisir Selatan, sebagian besar sampel $(86,36 \%)$ dari 286 ekor sampel memiliki kecocokan dalam subpopulasinya. Hanya sebagian kecil diantara sampel ini yang masuk ke subpopulasi lain, yakni 5,94 $\%$ dari anggota subpopulasi ini masuk ke subpopulasi Padang Pariaman dan 7,69 \% masuk ke subpopulasi Agam. Dari 111 sampel subpopulasi Padang Pariaman, sebahagian besar $(70,27 \%)$ sampel memiliki kesesuaian dalam subpopulasinya, 27,03 \% masuk ke subpopulasi Pesisir Selatan, dan sebahagian kecil $(2,70 \%)$ masuk ke subpopulasi Agam.

Dari 131 ekor sampel subpopulasi Agam hanya sebagian kecil $(39,69 \%)$ yang sesuai dalam subpopulasinya. Sebagian besar
$(51,91 \%)$ dari anggota subpopulasi ini masuk ke subpopulasi Pesisir Selatan, dan sebagian kecil $(8,40 \%)$ masuk ke subpopulasi Padang Pariaman. Hal ini mengindikasikan bahwa subpopulasi sapi Pesisir Selatan dan Agam memiliki tingkat kesamaan morfologi lebih tinggi dibanding dengan subpopulasi Padang Pariaman.

Ditinjau dari analisis jarak antar kelompok, Tabel 2 berikut menunjukkan bahwa jarak terbesar diperlihatkan antara subpopulasi Padang Pariaman dan Agam $(5,37)$, kemudian diikuti antara subpopulasi Pesisir Selatan dan Padang Pariaman $(4,44)$ dan terendah antara Pesisir Selatan dan Agam $(1,06)$. Hal ini menunjukkan bahwa diantara ke tiga subpopulasi sapi pesisir Sumatera Barat, subpopulasi Pesisir Selatan memiliki hubungan yang relatif lebih dekat dengan subpopulasi Agam dibandingkan hubungan antara subpopulasi Padang Pariaman dengan subpopulasi Pesisir Selatan dan Agam.

Sebagaimana dikemukakan pada hasil analisis di atas, antara subpopulasi Pesisir Selatan dan Agam memiliki tingkat kesamaan morfologi lebih tinggi dibandingkan antara ke 
dua subpopulasi ini dengan subpopulasi Padang Pariaman.

Hasil ini mengindikasikan bahwa ternak sapi pada ke dua subpopulasi Pesisir Selatan dan Agam ini diduga berasal dari moyang yang sama. Sebaliknya, memisahnya ukuran - ukuran morfologi sapi pada sub populasi Padang Pariaman dari ke dua subpopulasi Pesisir Selatan dan Agam mungkin disebabkan oleh karena ternak sapi di daerah ini telah banyak bercampur dengan bangsa - bangsa sapi lain, baik melalui program inseminasi buatan dan/atau perkawinan alam. Hal ini mungkin disebabkan karena wilayah Padang Pariaman sejak lama lebih terbuka dan pola beternak masyarakatnya sudah lebih maju dibanding Pesisir Selatan dan Agam.

Dari Tabel 2 dapat dikontruksi pohon jarak yang menggambarkan hubungan antar ketiga subpopulasi sapi lokal Sumatera Barat sebagaimana disajikan pada Gambar 1. Konstruksi pohon jarak ini semakin memperjelas lebih eratnya hubungan antara subpopulasi Pesisir Selatan dan Agam dibandingkan dengan hubungan antara subpopulasi Pesisir Selatan dengan subpopulasi Padang Pariaman.

Tabel 2. Jarak Antar Subpopulasi Sapi Lokal Sumatera Barat

\begin{tabular}{lccc}
\hline & \multicolumn{3}{c}{ Subpopulasi } \\
\cline { 2 - 4 } Subpopulasi & Pesisir Selatan & Padang Pariaman & Agam \\
\hline Pesisir Selatan & 0 & 4,44 & 1,06 \\
Padang Pariaman & & 0 & 5,37 \\
Agam & & & 0 \\
\hline
\end{tabular}

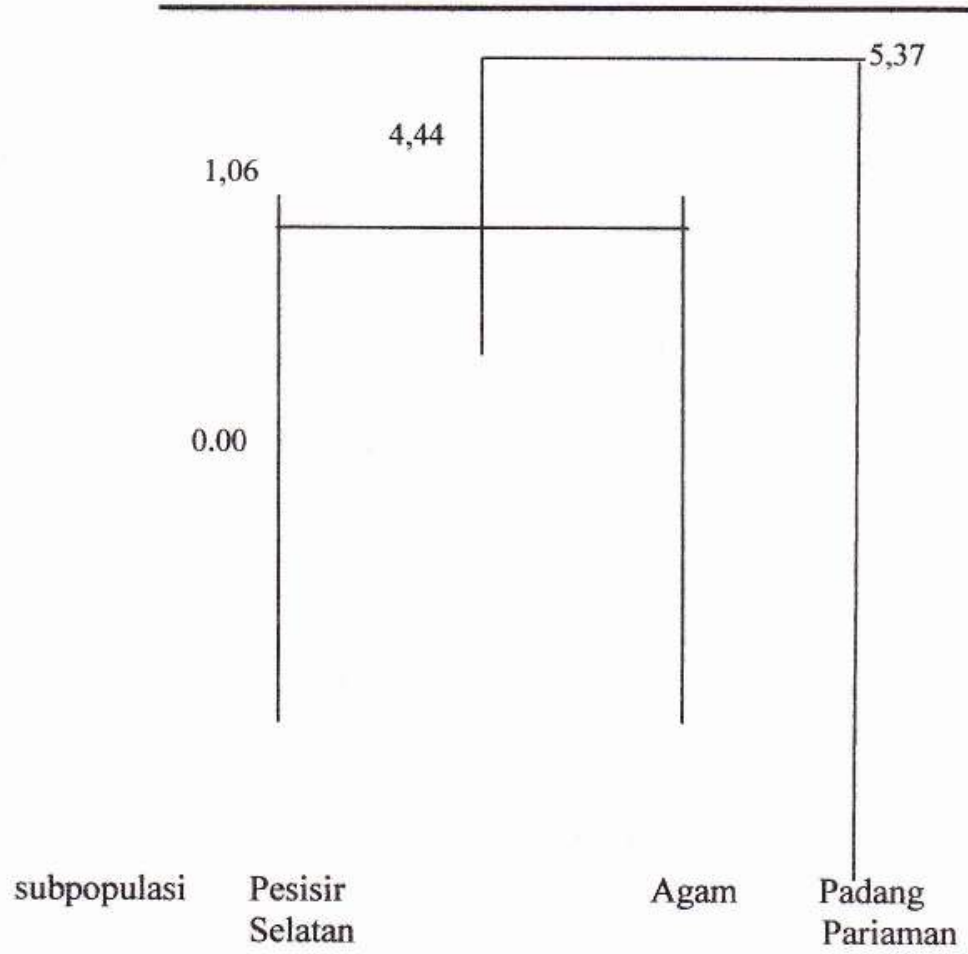

Gambar 1. Pohon Jarak Antar Ke Tiga Subpopulasi Sapi Lokal Sumatera Barat 
Analisis Peubah Pembeda Antar Subpopulasi Sapi Lokal Sumatera Barat

Hasil analisa korelasi kanonik antar ukuran tubuh yang menyebabkan perbedaan antar subpopulasi disajikan pada Tabel 3.

Nilai korelasi kanonik pada satu peubah mengindikasikan kontribusi peubah-peubah tersebut sebagai pembeda antar kelompok atau subpopulasi. Berdasarkan pada Tabel 3 di atas dapat dikemukakan bahwa pada fungsi kanonik 1 ditemukan beberapa peubah dengan korelasi kanonik yang relatif tinggi, yaitu berturut-turut dari yang tertinggi adalah: tinggi pundak $(0,677)$; tinggi pinggul $(0,649)$; lebar kepala $(0,543)$; bobot badan $(0,535)$; serta panjang kepala (0,518). Hasil ini menggambarkan bahwa ukuran tubuh yang paling berperan sebagai pembeda subpopulasi sapi Pesisir Sumatera Barat, secara berurutan dari yang terkuat atau terpenting adalah: tinggi pundak, tinggi pinggul, lebar kepala, bobot badan dan panjang kepala. Sebaliknya, beberapa peubah lainnya pada peubah kanonik 1 (panjang badan, lingkar dada, lingkar pinggul, dalam dada, dalam pinggul, lebar dada, dan lebar pinggul), dan semua peubah pada fungsi kanonik 2 memiliki nilai korelasi kanonik yang relatif rendah, berkisar dari $-0,038$ sampai dengan 0,422 . Hal ini menunjukkan bahwa peubah-peubah ini kurang berperan sebagai peubah pembeda antar subpopulasi sapi lokal Sumatera Barat.

\section{Kesimpulan}

Dari penelitian ini dapat
disimpulkan perbedaan subpopulasi yang cukup besar antara subpopulasi Padang Pariaman dan Agam, tetapi ada kesamaan yang cukup tinggi antara subpopulasi Pesisir Selatan dan Agam. Tinggi pundak, tinggi pinggul, lebar kepala dan panjang kepala adalah ukuran-ukuran tubuh yang memiliki peranan utama sebagai pembeda antar subpopulasi sapi Pesisir di Sumatera Barat.

Tabel 3. Struktur Total Kanonik Ukuran-Ukuran Tubuh Sapi Lokal Sumatera Barat

\begin{tabular}{lcc}
\hline \multicolumn{1}{c}{ Peubah } & Kanonik 1 & Kanonik 2 \\
\hline Bobot badan & 0,535470 & 0,250161 \\
Panjang badan & 0,342522 & 0,274127 \\
Lingkar dada & 0,422109 & 0,166837 \\
Lingkar pinggul & 0,315458 & 0,209128 \\
Tinggi pundak & 0,677485 & 0,137957 \\
Tinggi pinggul & 0,649669 & 0,320020 \\
Dalam dada & 0,207003 & 0,297473 \\
Dalam pinggul & 0,151245 & 0,369574 \\
Lebar dada & 0,380323 & $-0,341523$ \\
Lebar pinggul & 0,113841 & $-0,038113$ \\
Panjang kepala & 0,517587 & $-0,182427$ \\
Lebar kepala & 0,543441 & 0,294972 \\
\hline
\end{tabular}




\section{Daftar Pustaka}

BPS Tingkat I Sumatera Barat. 2001. Sumatera Barat Dalam Angka.

Fapet IPB Ditjennak. 1985. Standarisasi Bibit Sapi Lokal. Departemen Pertanian, Jakarta.

Herrera, M., E. Rodero, M.J. Guttierrez, F. Peria, and J.M. Rodero. 1996. Application of multifactorial discriminant analysis in the morphostructural differentiation of Andalusian caprine breeds. Small Rum. Res. 22: $39-47$.

Lebart, L., Alain, M. and Kenneth, M.W. 1984. Multivariate Descriptive Statistical Analysis. John Wiley \& Sons. New YorkChichester-Brisbane-TorontoSingapore.

Manly, B.F.J. 1986. Multivariate Statistical Methods: A Primer. Chapman and Hall.London New York.

Siregar, A.R., C. Talib, K. Diwyanto, P.Sitepu, H. Prasetyo, U. Kusnadi, P. Sitorus dan D. Budiwiyono. 1985. Performance Sapi Madura di Pulau Madura. Direktorat Jendral Peternakan dan Balai Penelitian Ternak. Penelitian dan Pengembangan Pertanian, Jakarta.

Siswadi dan B. Suharjo. 1997. Analisis Eksplorasi Data Peubah Ganda. FMIPA (IPB)

Steel, R.G.D., dan J.H. Torrie. 1995. Prinsip dan Prosedur Statistika: Suatu pendekatan biometrik. Edisi kedua. PT. Gramedia. Jakarta.

Suparyanto, A., T. Purwadaria, dan Subandriyo. 1999. Pendugaan Jarak Genetik dan Faktor Peubah Pembeda Bangsa dan Kelompok Domba di Indonesia Melalui Pendekatan Analisis Morfologi. J. Ilmu Ternak dan Veteriner 2 (4): 80-87.

Utoyo, D.P., Djarsanto, dan S.N. Nasution. 1996. Animal Genetic Resources and Domestic Animal Diversity in Indonesia. Ministry of Agriculture, Directorate General of Livestock Services, Directorate of Livestock Breeding Development. Jakarta.

Wiley, E.O. 1981. Phylogenetics: The Theory and Practice of Phylogenetic Systematics. John Wiley \& Sons Inc. Canada.

Alamat korespondensi: Dr.Ir. Sarbaini, M.Sc

Jurusan Produksi Ternak Fakultas Peternakan

Universitas Andalas, Kampus Limau Manis, Padang

Diterima: 2 Januari 2007, Disetujui: 5 Februari 2007 